percentage in the urine resulted from concentration by reabsorption of fluid. The high figures for protein in oedema fluids of acute nephritis were difficult to understand: they would suggest a considerable loss of protein from the blood which was not really observed in the early stages of acute nephritis. In famine oedema, referred to by Dr. Smirk, the plasma proteins were low, as in nephrosis, but even in that case the low osmotic pressure would not by itself account for excess retention of fluid in the body. There was no doubt a polyuria, indicating good renal capacity for elimination of fluid, but the amount excreted was less than the fluid intake. Retention here might be due to insufficiency of the natural diuretic urea in the renal filtrate.

Dr. W. E. Carnegie Dickson showed a series of lantern slides illustrating variability and multiplicity in certain intracranial tumours. He was followed by $\mathrm{Dr}$. T. B. DAVIE (Liverpool), who considered the criteria of malignancy in cerebral tumours, and by Mr. A. B. CLERY (Dublin), who discussed the question from the surgical point of view.

\section{SECTION OF OTO-RHINO-LARYNGOLOGY}

Friday, July 28th

TUBERCulosis OF THE LARYNX

With the President, Sir Robert Woods (Dublin), in the chair, Mr. R. Scott Stevenson opened the discussion on the treatment of tuberculosis of the larynx. Quoting Sir StClair Thomson, he estimated that there were $\mathbf{7 8 , 8 1 9}$ persons in England and Wales suffering from tuberculosis of the larynx. He said that the greatest advance in treatment since the introduction of sanatoriums was the production of artificial pneumothorax. It was the patient who had to be treated rather than the larynx, and for this reason an institutional regime was greatly preferable to out-patient treatment. After stressing the importance of early laryngeal examination, he then went on to discuss the methods of treatment. Vocal rest was one of the most valuable of these, and should be rigidly enforced if possible. Local treatment by the galvano-cautery was valuable in selected. cases, but he had abandoned diathermy. After a careful and detailed survey of the literature and methods employed by Strandberg. Wessely, and others, Mr. Scott Stevenson had come to the conclusion that the results achieved by artificial sunlight were little better than those obtained by vocal rest and ative treatment of the main disease.

Dr. F. R. G. Heaf, dealing with the prognosis of the disease, said that whereas forty years ago tuberculosis of the Iarynx was always regarded as incurable, this was not so to-day. He then discussed the factors in prognosis, stressing in particular the value of serial blood examinations. If these showed (1) a rapid sedimentation rate, (2) a high monocyte count, and (3) a low lymphocyte and eosinophil count, the prognosis was bad. Other factors were: the amount and type of pulmonary disease, the character and site of the lesion, the presence or absence of ulceration, the temperament of the patient, alcoholism, excessive smoking, occupation, etc. Cases affecting the aryteno-epiglottic region were mostly hopeless, especially in the young, while cases mainly corditic and interarytenoid usually did better. Localized lesions were better. than generalized, and in lupoid cases one could give a reasonably favourable prognosis. Finally, he stressed the points that early diagnosis, efficient treatment of the main disease, and eradication of focal sepsis were of the greatest value.

Dr. C. D. S. Agassiz, discussing the frequency of the disease in children, said that the amount of tuberculous laryngitis in children was grossly underestimated. He had examined eighty-six girls between the ages of 11 and 16 years and had found fifteen with laryngeal signs. About 20 per cent. of children with a positive sputum had laryngeal signs. Nearly $\mathbf{5 0}$ per cent. of his cases showed no symptom whatever, and would have been missed unless the condition had been looked for. The prognosis was fairly good; as a rule only general treatment was available.
Dr. P. J. KEOGH (Dublin) said that the main principles in treatment were: (1) silence, (2) the co-operation of a first-class physician, and (3) the judicious and timely use of the galvano-cautery. Chaulmoogra oil in his hands had been fairly successful ; he had not had much result from nerve block, and the results of artificial sunlight needed a great deal more investigation. Mr. H. S. BARWEL stressed the importance of sanatorium treatment. He very much doubted whether whispering was any less strain than gentle talking, and did not advocate its use. Dysphagia was best treated by orthoform: anaesthesin and euphagin were also good. In the severe pain associated with flask-shaped swelling of the arytenoids and ulceration of the epiglottis, by far the best results were obtained by removal of the most painful spot with punch forceps under local anaesthesia. Injection of the superior laryngeal nerve was occasionally good, but tracheotomy should never be performed except for the most urgent dyspnoea. Dr. J. R. WHEELER (Belfast) gave some figures showing the relation between laryngitis and severe chest lesions. Phrenic avulsion, thoracoplasty, and artificial pneumothorax greatly improved the prognosis. He agreed with Dr. Heaf in commending the great value of serial blood examinations. $\mathrm{He}$ advocated early removal of septic foci. Mr. P. J. Dempsey (Dublin) agreed that forced whispering was dangerous, and that it was impossible to evaluate any particular method of treatment by itself. Lactic acid paints were bad, and so were the extensive operations formerly in favour. He never removed septic tonsils in the presence of active tuberculosis. Mr. A. D. Sharp (Leeds) disagreed on the question of septic foci, and advocated their removal ; he had seen good results from local application of ultra violet light, and thought the galvano-cautery a very useful weapon ; he even employed lactic acid in certain cases. Dr. J. B. Horgan (Cork) gave some interesting figures on the frequency of tuberculous infections of the nasopharynx in the post-mortem room, and hoped the young practitioner would soon learn to use the laryngoscope.

Sir Robert Woods (Dublin) stressed the fact that it was the chronicity of the lesion that prevented it from healing, and that active local treatment with a view to producing an inflammatory reaction was indicated. For this reason he approved of the galvano-cautery, and had been getting very good results with deep $x$-ray therapy. Dr. R. R. TRAILl (Midhurst) gave an interesting case report showing the value of artificial pneumothorax in an apparently hopeless case. He had not had good results with artificial sunlight. Mr. R. R. Woovs (Dublin) said that it was the patient that cured the disease and not, the laryngologist. The best general treatment was indicated. The meeting closed with a film made by Dr. William Beaumont and presented by Mr. J. F. O'MaLley on the treatment of tuberculosis of the larynx by means of the Kromayer lamp.

\section{Corrigendum}

Owing to an error Dr. M. A. Cassidy was reported (Journal, August 5th, p. 247) to have said, at the discussion on essential vascular hypertension at the Section of Medicine that: "A night urine of low specific gravity which remained fixed after the patient had drunk a pint of water was more ominous". This should have read: "A night urine of low specific gravity and a specific gravity which remained fixed at about 1010 after drinking a pint of water were more ominous."

The L.C.C. recently authorized the employment as and from July of this year of a consulting surgeon at its hospital for children at Margate and at St. Luke's Hospital, Lowestoft, to visit the hospitals as required, and to be paid for each visit two guineas for a consultation or three guineas for an operation (including consultation). It is not intended to make individual appointments, but to authorize the medical superintendents of the hospitals to call in a local specialist as need arises. It is considered that on rare occasions it may be necessary to call in a consulting phrisician, and provision for this has been made. 